\title{
Avaliação da sinergia entre a engenharia de processos e o processo de pensamento da teoria das restrições
}

\author{
Daniel Pacheco Lacerdaa,*, Luis Henrique Rodrigues ${ }^{\mathrm{b}}$, Alexandre Costa da Silva ${ }^{\mathrm{c}}$ \\ a,*dlacerda@unisinos.br, UNISINOS, Brasil \\ blhr@unisinos.br, UNISINOS, Brasil \\ calexandres@unisinos.br, UNISINOS, Brasil
}

\begin{abstract}
Resumo
Este trabalho apresenta uma aplicação da utilização dos conceitos da engenharia de processos de negócios (EPN) e do processo de pensamento da Teoria das Restrições (PP-TR) para uma abordagem sistemática e sistêmica dos processos analisados. A EPN contribui como instrumento de ação nas organizações através da identificação e representação dos processos existentes. A modelagem dos processos constrói uma visão integrada e possibilita uma discussão e análise sistemática dos processos. 0 PP-TR é utilizado na análise crítica dos processos. Essa análise contribui para o entendimento e identificação das causas que sustentam as problemáticas existentes nos processos, proporcionando uma visão sistêmica do processo. Na pesquisa foram modelados processos de uma instituição de ensino superior (IES). Um processo foi analisado a partir da construção da Árvore da Realidade Atual (ARA). Em seguida aplicou-se a técnica da evaporação das nuvens para romper os pressupostos que mantinham os problemas identificados. Com base na ARA e na evaporação das nuvens os processos foram resenhados. Os resultados da abordagem forneceram: i) uma sistemática na análise dos processos; e ii) uma visão sistêmica da influência dos problemas encontrados nos processos entre si e no resultado da IES estudada.
\end{abstract}

Palavras-chave

Teoria das restrições. Engenharia de processos. Processo de pensamento. Análise de processos. Melhoria de processos.

\section{Introdução}

0 processo de pensamento da Teoria das Restrições é um conjunto de ferramentas que permite identificar, analisar e propor soluções aos problemas organizacionais (WATSON; BLACKSTONE; GARDINER, 2007; ANTUNES Jr. et al., 2004). Noreen, Smith e Mackey (1996) e Kim, Mabin e Davies (2008) relatam diversos casos de aplicação do processo de pensamento para a resolução de problemas específicos da organização.

Entretanto, não há uma sistematização do uso dessa ferramenta para a organização como um todo. Embora seja uma abordagem sistêmica na resolução de problemas, a Teoria das Restrições em seu arcabouço não sistematiza sua utilização para as áreas ou processos organizacionais. Realizar uma análise dos efeitos indesejados e suas causas em nível de processo pode contribuir para seu entendimento e para suas relações com outros processos organizacionais.

Nesse contexto, a engenharia de processos pode cooperar efetivamente para servir como elemento condutor das análises organizacionais em nivel de processos, contribuindo para o processo de pensamento da Teoria das Restrições. A visão por processos privilegia a análise das atividades transversais à organização, permitindo o entendimento e a melhoria da organização como um todo.

0 objetivo desse trabalho é, portanto, apresentar um caso de integração da engenharia de processos com o processo de pensamento da Teoria das Restrições, destacando a complementaridade das 
duas teorias e seus benefícios para a organização. As melhorias que podem ser elencadas são: i) melhor compreensão dos processos; ii) uma visão sistêmica dos problemas encontrados nos processos; e por consequência; iii) um melhor redesenho dos processos. Para isso realizou-se um estudo de caso em uma instituição de ensino superior, onde foram modelados os processos e aplicaram-se os conceitos das duas teorias em questão. Assim, foi possivel ter uma visão integrada dos processos e dos efeitos indesejados que estes ocasionam na organização pesquisada. Consequentemente, os processos foram redesenhados de forma mais consistente, buscando atuar nos pontos de alavancagem do sistema.

\section{Referencial teórico}

A seguir são apresentados os dois pilares teóricos desse trabalho: i) o processo de pensamento da Teoria das Restrições; e ii) conceituações referentes à engenharia de processos.

\subsection{O processo de pensamento da Teoria das Restrições}

A Teoria das Restrições é uma filosofia de gestão (GUPTA; BOYD, 2008) que tem evoluído em diferentes áreas ao longo do tempo (WATSON; BLACKSTONE; GARDINER, 2007). Possivelmente uma das áreas em que a Teoria das Restrições obteve maior visibilidade seja na de programação e sincronização da produção por meio do método TPC (tambor-pulmão-corda) (CHAKRAVORTY; BRIAN ATWATER, 2006; GOLDRATT, 2009). Por sua vez, o processo de pensamento da Teoria das Restrições é uma temática que tem apresentado crescimento significativo nos últimos anos (KIM; MABIM; DAVIES, 2008).

Para Antunes Jr. et al. (2004) e Lacerda (2005), o processo de pensamento da Teoria das Restrições pode ser considerado como um método de identificação, análise e solução de problemas. 0 processo de pensamento é um método que procura facilitar a liberação, focalização e a intuição, é um conjunto de ferramentas em que se busca promover a verbalização do bom senso (GOLDRATT, 1990, 1991, 2004). Para Cox e Spencer (2002), o processo de pensamento é um conjunto de ferramentas que podem ser utilizadas individualmente ou estarem ligadas de modo lógico, permitindo a identificação de problemas centrais, determinação de soluções do tipo ganha-ganha e na determinação e superação dos obstáculos possíveis para implementação da solução.
0 processo de pensamento baseia-se no método científico e busca responder a três perguntas: o que mudar?, para o que mudar? e como provocar a mudança? A lógica do processo de pensamento baseia-se em relações de efeito-causa-efeito e na visão crítica da realidade, em que se procura saber por que as coisas acontecem e não como elas acontecem (ALVAREZ, 1995; MUSA; EDMONDSON; MUCHUS, 2006).

Conforme Cox e Spencer (2002), a Teoria das Restrições possui cinco ferramentas que visam responder a essas três perguntas fundamentais; elas estão representadas no Quadro 1. As ferramentas empregadas são sustentadas em dois pontos centrais: a visão crítica da realidade e a análise efeitocausa-efeito (ALVAREZ, 1995; LACERDA, 2005). Para os fins desse trabalho apresentam-se a Árvore da Realidade Atual e a evaporação das nuvens.

\subsection{1. Árvore da Realidade Atual (CRT - Current Reality Tree)}

0 objetivo da Árvore da Realidade Atual (ARA) é a definição dos problemas centrais encontrados em um sistema específico (ANTUNES Jr. et al., 2004; BLACKSTONE, 2001). A construção da Árvore da Realidade Atual deve ser feita em grupos interfuncionais, proporcionando efetiva comunicação dos principais problemas da empresa e um entendimento comum desses problemas (KINGMAN, 1996; RODRIGUES, 2004).

Noreen, Smith e Mackey (1996) e Cox e Spencer (2002) apresentam um conjunto de passos que auxiliam na construção da ARA. 0 Quadro 2 reproduz a proposição dos passos na visão dos autores. Realizando o cotejo entre a proposição de Noreen, Smith e Mackey (1996) e Cox e Spencer (2002), percebe-se uma complementaridade na confecção dos passos para a construção da Árvore

Quadro 1. Cinco ferramentas do processo de pensamento.

\begin{tabular}{|c|c|}
\hline $\begin{array}{c}\text { Pergunta } \\
\text { central }\end{array}$ & Ferramenta \\
\hline 0 que mudar? & $\begin{array}{c}\text { Árvore da Realidade Atual } \\
\text { (CRT - Current Reality Tree) }\end{array}$ \\
\hline \multirow{2}{*}{$\begin{array}{c}\text { Para o que } \\
\text { mudar? }\end{array}$} & $\begin{array}{c}\text { Evaporação das nuvens } \\
\text { (Evaporating Clouds) }\end{array}$ \\
\cline { 2 - 2 } & $\begin{array}{c}\text { Árvore da realidade futura } \\
\text { (FRT - Future Reality Tree) }\end{array}$ \\
\hline \multirow{3}{*}{$\begin{array}{c}\text { Como provocar } \\
\text { a mudança? }\end{array}$} & $\begin{array}{c}\text { Árvore dos pré-requisitos } \\
\text { (PRT - Prerequisite Tree) }\end{array}$ \\
\cline { 2 - 3 } & Árvore de transição \\
& (TT - Transition Tree) \\
\hline
\end{tabular}

Fonte: adaptado de Cox e Spencer (2002). 
Quadro 2. Passos para construção da Árvore da Realidade Atual.

\begin{tabular}{|c|c|c|}
\hline Passo & Proposição Noreen, Smith e Mackey (1996) & Proposição Cox e Spencer (2002) \\
\hline 1 & $\begin{array}{l}\text { Faça uma lista de cinco a dez efeitos indesejáveis } \\
\text { (Els) que descrevam a área analisada e submeta } \\
\text { cada um deles à ressalva de existência da entidade. }\end{array}$ & $\begin{array}{l}\text { Liste cinco a dez problemas chamados efeitos indesejáveis } \\
\text { (Els) relacionados com a situação. }\end{array}$ \\
\hline 2 & $\begin{array}{l}\text { Se encontrar alguma conexão aparente entre os } \\
\text { dois ou mais Els conecte este "grupo" enquanto faz } \\
\text { o escrutínio de cada entidade e flecha ao longo do } \\
\text { caminho. Caso contrário escolha um El e ao acaso e } \\
\text { prossiga o passo } 3 .\end{array}$ & $\begin{array}{l}\text { Teste a clareza de cada El. O El é uma afirmação clara e } \\
\text { concisa? Esse teste é o chamado de ressalva de clareza. }\end{array}$ \\
\hline 3 & $\begin{array}{l}\text { Conecte todos os outros Els ao resultado do passo } \\
\text { 2, fazendo o escrutínio de cada entidade e flecha } \\
\text { ao longo do processo. Pare quanto todos os Els } \\
\text { estiverem ligados. }\end{array}$ & Procure alguma relação causal entre quaisquer dos Els. \\
\hline 4 & $\begin{array}{l}\text { Leia a árvore de "baixo para cima”, fazendo } \\
\text { novamente o escrutínio de cada flecha e entidade ao } \\
\text { longo do percurso. Proceda às correções necessárias. }\end{array}$ & $\begin{array}{l}\text { Determine qual El é a causa e qual é o efeito. Leia como "SE } \\
\text { causa, ENTÃO efeito". Esse teste é chamado de ressalva de } \\
\text { causalidade. Ocasionalmente a causa e o efeito podem ser } \\
\text { revertidos. Avalie utilizando a seguinte afirmação: "Efeito" } \\
\text { PORQUE "Causa" }\end{array}$ \\
\hline 5 & $\begin{array}{l}\text { Pergunte a si mesmo se a árvore como um todo } \\
\text { reflete a sua intuição sobre a área. Se não, verifique } \\
\text { cada flecha para descobrir ressalvas de causa } \\
\text { adicional. }\end{array}$ & $\begin{array}{l}\text { Continue o processo de conexão dos Els utilizando a lógica } \\
\text { SE-ENTÃo até que todos os Els estejam conectados. }\end{array}$ \\
\hline 6 & $\begin{array}{l}\text { Não hesite em expandir a sua árvore, para conectar } \\
\text { outros Els existentes mas que NÃo foram incluídos } \\
\text { na lista original de Els. Observação: Não dê este } \\
\text { passo até que todos os efeitos indesejados originais } \\
\text { estejam conectados. }\end{array}$ & $\begin{array}{l}\text { Frequentemente, a causalidade é forte para a pessoa que } \\
\text { sente o problema, mas parece não existir para os outros. } \\
\text { Nessas circunstâncias, a "clareza" é o problema. Utilize a } \\
\text { ressalva de clareza para eliminar o problema. Geralmente, } \\
\text { faltam entidades entre a causa e o efeito. }\end{array}$ \\
\hline 7 & $\begin{array}{l}\text { Reexamine os Els. Identifique as entidades na árvore } \\
\text { que sejam intrinsecamente negativas, mesmo que a } \\
\text { entidade não constasse na lista original de Els, ou } \\
\text { que ela requeira que a árvore seja expandida para } \\
\text { cima, uma ou duas entidades. }\end{array}$ & $\begin{array}{l}\text { Algumas vezes, a própria causa pode não ser suficiente } \\
\text { para criar o efeito. Esses casos são testados com a ressalva } \\
\text { de insuficiência de causa e são aprimorados lendo-se } \\
\text { da seguinte forma: "SE causa E } \text { ENTÃO". Esse "E" } \\
\text { conceitual é representado por uma linha horizontal que } \\
\text { corta ambos os conectores entre o efeito e as causas. }\end{array}$ \\
\hline 8 & $\begin{array}{l}\text { Elimine da árvore quaisquer entidades que não } \\
\text { sejam necessárias para conectar todos os Els. }\end{array}$ & $\begin{array}{l}\text { Algumas vezes, o efeito é causado por muitas causas } \\
\text { independentes. As relações são fortalecidas pela ressalva de } \\
\text { causa adicional. }\end{array}$ \\
\hline 9 & $\begin{array}{l}\text { Apresente a árvore para alguém que o ajude a fazer } \\
\text { aflorar e desafiar os pressupostos encontrados nela. }\end{array}$ & $\begin{array}{l}\text { Algumas vezes, um relacionamento SE-ENTÃo parece lógico, } \\
\text { mas a causalidade não é apropriada da maneira como está } \\
\text { escrita ou verbalizada. Nessas circunstâncias palavras como } \\
\text { "alguns", "poucos", "muitos", "frequentemente", "algumas } \\
\text { vezes" e outros modificadores podem fazer a causalidade se } \\
\text { tornar mais forte. }\end{array}$ \\
\hline 10 & $\begin{array}{l}\text { Examine todos os pontos de entrada da árvore e } \\
\text { decida quais os que deseja atacar. Escolha entre eles } \\
\text { o que contribui mais para a existência dos Els. }\end{array}$ & $\begin{array}{l}\text { A numeração dos Els na ARA serve apenas para facilitar a } \\
\text { localização destes. Um asterisco no El indica que aquele El } \\
\text { faz parte da lista original dos Els. }\end{array}$ \\
\hline
\end{tabular}

Fonte: Noreen, Smith e Mackey (1996, p. 154), e Cox e Spencer (2002, p. 253).

da Realidade Atual. Segundo Noreen, Smith e Mackey (1996), as flechas são os indicativos de suficiência, isto é, para que ocorra um determinado efeito indesejado é necessária a ocorrência de outro (individualmente, simultaneamente ou ambos).

Para que a Árvore da Realidade Atual esteja concisa e correta, é necessário que se façam algumas consistências. Essas consistências são utilizadas para validação e nivelamento do entendimento da ARA e são demonstradas no Quadro 3. É possível, ainda, a inclusão de ressalvas legítimas, que são entidades (efeito ou causa) e relacionamentos, inseridos para facilitar a compreensão.

Para Klein e DeBruine (1995) e Cox e Spencer (2002), a Árvore da Realidade Atual construída, completamente, fornece mecanismos para: i) identificar o impacto de políticas, procedimentos e ações na organização; ii) comunicar, clara e concisamente, a causalidade dessas políticas, procedimentos e ações; iii) identificar o problema central em uma situação; e iv) permitir a criação de um clima favorável de relação frente aos problemas, 
Quadro 3. Quadro de consistências da Árvore da Realidade Atual.

\begin{tabular}{|c|c|c|}
\hline llustração & Consistência & Descrição \\
\hline & Existência de entidade & $\begin{array}{l}\text { Validar a real existência da entidade (efeito ou causa), verificando } \\
\text { se a causa e/ou o efeito existem realmente. }\end{array}$ \\
\hline & $\begin{array}{l}\text { Existência de } \\
\text { causalidade }\end{array}$ & $\begin{array}{l}\text { Consistir a presença do elo causal entre o efeito e a causa, } \\
\text { utilizando-se da declaração SE-ENTÃO. Deve-se verificar se há } \\
\text { uma ligação direta entre o efeito observado e a causa afirmada. }\end{array}$ \\
\hline & Tautologia & $\begin{array}{l}\text { Evitar ser redundante na relação causa-efeito. A tautologia é na } \\
\text { verdade uma repetição do efeito, isto é, a causa é o efeito e o } \\
\text { efeito é a causa. Esse tipo de situação deve ser evitado, pois, sendo } \\
\text { assim, a causa não produz efeito. }\end{array}$ \\
\hline & $\begin{array}{l}\text { Existência de efeito } \\
\text { predito (previsto) }\end{array}$ & $\begin{array}{l}\text { Isso pode ser feito utilizando-se outro efeito para demonstrar que } \\
\text { a causa não produza o efeito observado ou ainda para demonstrar } \\
\text { que a causa gera um efeito que apoia a relação efeito-causa } \\
\text { original. }\end{array}$ \\
\hline & $\begin{array}{c}\text { Suficiência ou } \\
\text { insuficiência de causa }\end{array}$ & $\begin{array}{l}\text { Essa consistência demonstra que para a existência do efeito } \\
\text { indesejado é necessária a combinação de duas causas. Isso } \\
\text { demonstra que outra causa existe para explicar o efeito observado. } \\
\text { Esse gráfico deve ser lido da seguinte forma: SE causa E causa } \\
\text { ENTÃO. }\end{array}$ \\
\hline & Causa adicional & $\begin{array}{l}\text { Esse tipo de relação demonstra que qualquer uma das causas pode } \\
\text { acarretar na ocorrência do efeito indesejado. Esse efeito irá ocorrer } \\
\text { e poderá ser mais ou menos intenso em função da combinação } \\
\text { das causas. Esse gráfico deve ser lido da seguinte forma: SE causa } \\
\text { OU causa ENTÃO. }\end{array}$ \\
\hline & $\begin{array}{l}\text { Esclarecimento ou } \\
\text { claridade }\end{array}$ & $\begin{array}{l}\text { Compreender claramente a relação causa-efeito ou a própria } \\
\text { existência da entidade. Se for o caso, formular uma explicação } \\
\text { adicional da relação causa-efeito, da relação ou da entidade }\end{array}$ \\
\hline
\end{tabular}

Fonte: adaptado de Noreen, Smith e Mackey (1996) e Alvarez (1995).

colocando toda a massa crítica contra o problema central.

Noreen, Smith e Mackey (1996) ressaltam ainda que a Árvore da Realidade Atual deve ser construída de maneira top-down, entretanto deve ser lida e compreendida de forma botton-up. Uma das formas de realizar a consistência é apresentá-la a outras pessoas que não participaram da construção da árvore. A ARA é a combinação entre a lógica e as regras obtidas na prática por meio da tentativa e erro (NOREEN; SMITH; MACKEY, 1996). A seguir será apresentada, sucintamente, a evaporação das nuvens.

\subsubsection{Evaporação das nuvens (EC - Evaporating Clouds)}

Uma vez identificado o problema central, está respondida a pergunta “o que mudar?". 0 passo seguinte é "para o que mudar?”. Para responder a questão, utilizam-se as ferramentas: evaporação das nuvens e árvore da realidade futura. A evaporação das nuvens procura formular uma solução efetiva para eliminar o problema central (ANTUNES Jr. et al., 2004; KIM; MABIN; DAVIES, 2008). A evaporação das nuvens expõe os pressupostos não verbalizados que sustentam os problemas centrais. Em geral esses 
problemas centrais têm origem em um conflito de posições (ANTUNES et al., 2004; LACERDA, 2005). Alvarez (1995) complementa que para resolver esses problemas centrais (conflitos) utilizam-se soluções de compromisso.

As soluções de compromisso são decisões que são tomadas privilegiando uma posição conflitante em relação à outra. Portanto, são soluções conciliatórias que, em geral, foram implementadas em alguma tentativa de resolver o problema. $\mathrm{Na}$ atividade de gestão, há situações de trade-offs (quando o gestor deve escolher uma opção em detrimento de outra). Nessas situações, segundo a Teoria das Restrições, há sempre uma solução simples e criativa que rompe os pressupostos existentes em relação ao problema central (GOLDRATT, 1990, 1992; ALVAREZ, 1995; KLEIN; DEBRUINE, 1995; NOREEN; SMITH; MACKEY, 1996; COX; SPENCER, 2002; ANTUNES Jr. et al., 2004).

A Figura 1 representa um diagrama de evaporação das nuvens. Essa ferramenta busca soluções inovadoras (injeções) por meio do exercício da criatividade, buscando elementos que possam invalidar os pressupostos existentes. Dessa forma é possível construir soluções consistentes que não dependam de compromisso que, em geral, levam à solução perde-perde.

A interpretação da Figura 1 explicita que ambos os lados têm o mesmo objetivo em comum, entretanto, há pressupostos legítimos de ambos os lados que colocam as partes em conflito para a resolução do problema. Cox e Spencer (2002) ilustram essa relação nas seguintes afirmações: "Para cumprir A, devo cumprir B por causa da relação AB. Para cumprir B, devo cumprir D por causa do pressuposto BD" (COX; SPENCER, 2002, p. 263). Por outro lado: "Para cumprir A, devo cumprir C por causa da relação AC. Para cumprir C, devo cumprir D por causa do pressuposto CD" (COX; SPENCER, 2002, p. 263).

Para Goldratt (1991), o primeiro passo para resolver um problema é defini-lo claramente. Assim o próprio desenho da nuvem contribui para a definição do problema e o encontro de soluções. 0 Quadro 4 apresenta alguns passos para a construção do diagrama de evaporação das nuvens.

Realizados esses passos, chegam-se às injeções. Para a elaboração das injeções (soluções), não há nenhuma sequência ou técnica formal. Sugere-se a utilização do brainstorming, buscando-se soluções criativas (injeções) (ALVAREZ, 1995). Na sequência, serão evidenciados alguns aspectos sobre a engenharia de processos.

\subsection{Engenharia de processos}

Segundo Paim (2002), a engenharia de processos é entendida como uma arquitetura (framework) para compreensão, análise e melhoria dos processos internamente ou entre as organizações. Por meio da representação dos fluxos horizontais ou transversais de atividades e informações nas organizações, busca-se construir uma visão sistêmica de como as unidades de uma organização se integram, com vistas a gerar os resultados e agregar valor para os seus clientes finais.

Um processo é definido como uma específica ordenação de atividades de trabalho através

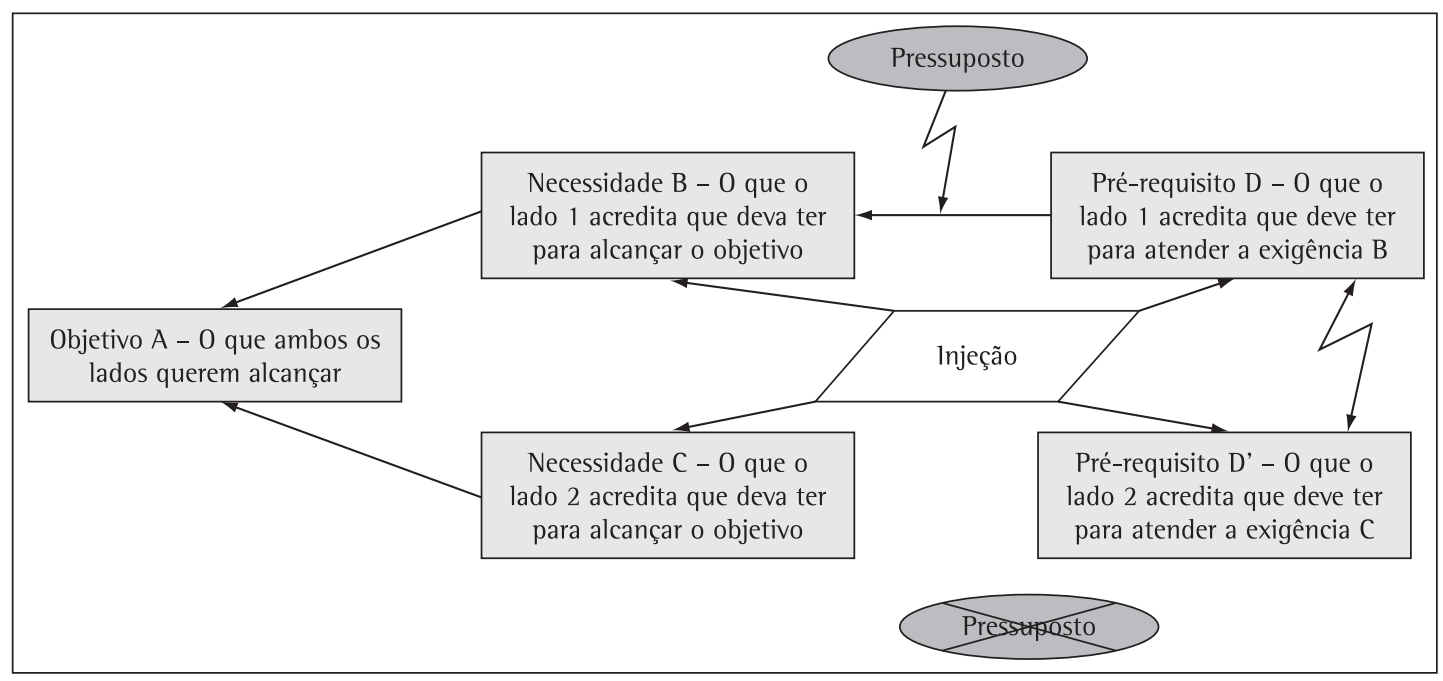

Figura 1. Representação genérica de um diagrama de evaporação das nuvens. Fonte: adaptado de Cox e Spencer (2002, p. 263). 
Quadro 4. Passos para construção do diagrama de evaporação das nuvens.

\begin{tabular}{|c|l|}
\hline Passo & \multicolumn{1}{|c|}{ Proposição Noreen, Smith e Mackey (1996) } \\
\hline 1 & $\begin{array}{l}\text { Definir o objetivo em comum. Em geral esse } \\
\text { objetivo é a proposição inversa ao problema central. }\end{array}$ \\
\hline 2 & $\begin{array}{l}\text { Explicitar os requisitos necessários para que o } \\
\text { objetivo em comum seja atingido. }\end{array}$ \\
\hline 3 & $\begin{array}{l}\text { Explicitar quais são os pré-requisitos existentes para } \\
\text { que os requisitos sejam atendidos; as relações entre } \\
\text { os requisitos e os pré-requisitos são os pressupostos } \\
\text { que sustentam as posições conflitantes. }\end{array}$ \\
\hline 5 & $\begin{array}{l}\text { Explicitar o conflito através dos requisitos, pré- } \\
\text { requisitos e principalmente dos pressupostos que } \\
\text { os sustentam. }\end{array}$ \\
\hline 5 & $\begin{array}{l}\text { Verbalizar esses pressupostos por trás da relação } \\
\text { efeito-causa que estão estabelecidos entre os } \\
\text { requisitos e os pré-requisitos. }\end{array}$ \\
\hline
\end{tabular}

Fonte: Goldratt (1990, 1991); Alvarez (1995); Mackness, Bowles e Rodrigues (1995); Goldratt (2004).

do tempo e do espaço, com início, fim e um conjunto, claramente definido, de entradas e saídas (DAVENPORT, 2000). Os processos podem ser melhor entendidos se percebidos como uma estruturação lógico-temporal de ações e recursos com o objetivo de gerar um ou mais produtos e/ou serviços para os clientes da organização (SALERNO, 1999; VILLELLA, 1994; PAIM, 2002; PAIM et al., 2009).

A crescente aplicação da engenharia de processos nas organizações resulta de uma necessidade de maior flexibilidade, coordenação de atividades e orientação para resultados integrados nas organizações. De certa forma, a abordagem por processos se contrapõe à estruturação das organizações funcionais. Por um lado a organização funcional potencializa o aumento de conhecimento especializado na medida em que agrupa os profissionais por especialidade técnica e prioriza os indicadores de desempenho departamentais. Por outro, não garante, necessariamente, um ótimo desempenho global da organização e, em alguns casos, pode estimular um comportamento de isolamento e de competitividade interna.

Por meio da identificação e representação dos processos da organização, a engenharia de processos visa fazer uma análise crítica dos processos da organização, com vistas a permitir a melhoria das operações (HAMMER; CHAMPY, 1994; DAVENPORT, 2000). Ela também propicia a gestão integrada para incrementar um desempenho sistemático e consistente (RUMMLER; BRACHE, 1995; DAVENPORT, 2000). A percepção da interdependência das atividades que acontecem no âmbito das funções permite e potencializa a discussão dos problemas e seus efeitos indesejados através da organização.

A visão por processos prioriza a análise das funções de uma organização desde uma óptica de atividades sequenciadas lógicotemporalmente (JOHANSSON, 1995; SALERNO, 1999; CAULLIRAUX; CAMEIRA, 2000). Dessa forma, busca otimizar não apenas as atividades localmente, mas contribuir para a melhoria dos produtos e serviços finais da organização. Grover e Kettinger (2000) apresentam como vantagens da aplicação de técnicas da engenharia de processos nas organizações: i) uniformização do entendimento da forma de trabalho; ii) maior integração; iii) maior facilidade para análise e melhoria do fluxo de informações; iv) explicitação do conhecimento sobre os processos, armazenando, assim, o know-how organizacional; v) realização de análises organizacionais e de indicadores; e vi) realização de simulações, apoiando a tomada de decisões e gestão da organização, de forma integrada. Segundo Paim, Caulliraux e Clemente (2003), encontram-se, ainda, entre os principais objetivos da engenharia de processos: i) construção de uma visão homogênea do negócio; ii) melhoria do fluxo de informações; iii) padronização dos processos; iv) melhoria da gestão organizacional; v) melhor conhecimento dos processos, aumento do conhecimento organizacional sobre processos; e vi) redução de custo e tempo dos processos.

\subsection{Modelagem de processos}

A modelagem de processos se apresenta como a principal ferramenta para a condução das ações de processos nas organizações. Tem por objetivo a sua representação, fornecendo insumos para análise e melhoria da forma de trabalho entre as diversas funções da organização (HUNT, 1996; VERNADAT, 1996). Segundo Paim et al. (2002), a modelagem de processos, atualmente, é suportada por ferramentas que sustentam, a partir de um referencial, o desenvolvimento de diferentes ações baseadas na lógica de processos.

Um modelo pode ser entendido como uma representação explícita e externa de parte da realidade vista por pessoas que desejam usar o modelo para: entender, mudar, gerenciar e controlar essa parte da realidade de alguma forma (PIDD, 1998). Os modelos de processos, nesse sentido, buscam representar os aspectos relevantes no âmbito da execução das atividades de uma determinada organização. Dessa forma, a modelagem de processos permite a geração de uma base para o desenvolvimento de ações 
baseadas em processos. Elas podem ser de melhoria dos próprios processos ou, ainda, de redefinição e criação de novos processos para a empresa. Dentre os principais objetivos da modelagem de processos, encontram-se (JOHANSSON, 1995; HUNT, 1996; VILLELLA, 2000; PAIM, 2002): melhor representar ou entender como uma organização (ou alguma parte dela) funciona; usar/explicitar o conhecimento adquirido e a experiência para usos futuros; racionalizar e assegurar o fluxo de informações; projetar ou reprojetar e especificar uma parte da organização (aspectos funcionais, comportamentais, informacionais, organizacionais ou estruturais); analisar alguns aspectos da organização (análises econômicas, organizacionais, quantitativas, qualitativa, layout e outras); simular o comportamento de algumas partes da organização; tomar melhores decisões sobre as operações e organização da empresa e controlar, coordenar ou monitorar algumas partes da organização (isto é, alguns processos).

As ações de modelagem de processo podem ser suportadas por diferentes métodos. Dentre as metodologias de modelagem comumente utilizadas encontram-se a ARIS (Arquitetura de Sistema de Informação Integrado), a Cimosa (Arquitetura Aberta de Sistemas), o IDEF (Métodos Integrados de Definição), o BPMn (TSCHESCHNER, 2006; OU-YANG; LIN, 2008), entre outras (PAIM, 2002). Independente da metodologia utilizada, um ponto importante e de convergência entre as diversas metodologias é o estabelecimento de uma linguagem comum e estruturada para a condução das ações de modelagem.

No âmbito dessas ações, deve haver uma uniformização dos níveis de detalhamento para a representação dos processos. Além disso, são necessárias a padronização dos modelos e a nomenclatura adotada. Essa definição está relacionada aos objetivos da modelagem, assim como o escopo de abrangência da modelagem na organização. Construir uma visão comum é requisito para gerar modelos de processos padronizados e garantir um entendimento dos profissionais que utilizarão os modelos de processos para compreender a realidade e, por consequência, realizar uma intervenção.

Em geral não é possível construir, a priori, uma visão de todos os processos que existem na organização. Essa construção ocorre, na maioria dos casos, por meio de uma abordagem bottom-up, isto é, uma descrição dos fluxos de atividades de cada unidade organizacional e da identificação das interfaces entre essas unidades que, de maneira progressiva, permitem a construção da visão integrada dos processos que transversalmente ocorrem na organização. No âmbito deste trabalho, a modelagem dos processos se colocou, justamente, como uma forma de melhor entender a realidade analisada e como instrumento de análise e proposição de melhorias de caráter sistêmico para a organização estudada.

\section{Abordagem metodológica}

Para atender o objetivo do trabalho de integrar o processo de pensamento da Teoria das Restrições e os conceitos da engenharia de processos, a abordagem adotada foi qualitativa. Desse modo, sua viabilização ocorreu utilizando os procedimentos do estudo de caso, no qual uma instituição de ensino superior (IES) serviu de objeto de análise da integração entre as duas teorias abordadas.

0 estudo de caso é um método apropriado para investigar e entender determinado fenômeno ou comportamento organizacional (EINSENHARDT, 1989, 1991; DYER JR.; WILKINS, 1991). Ele proporciona um entendimento do padrão do objeto pesquisado. Bryman (1988) considera a capacidade de proporcionar descrições detalhadas de um fenômeno como uma das principais características dos estudos qualitativos. Para isso é importante que o objeto de estudo seja passível de observação.

Além disso, o estudo de caso pode ser utilizado para a construção de teorias (EINSENHARDT, 1989; EINSENHARDT; GRAEBNER, 2007). Por ser uma técnica que desenvolve explanação e entendimento sobre determinado fenômeno, ela possibilita o nascimento de teorias. Einsenhardt (1989) apresenta a construção de diversas teorias a partir do estudo de casos. Ele pode ser utilizado para: i) explorar um determinado assunto ou problema, entendendo-o profundamente; ii) explanar sobre um fenômeno; iii) descrever um fenômeno; e iv) predizer características de um determinado fenômeno (ELLRAM, 1996; YIN, 2001; DUBE; PARE, 2003).

\subsection{Procedimentos técnicos e método de trabalho}

A Figura 2 apresenta, em geral, o método de trabalho utilizado para o desenvolvimento dessa pesquisa. 0 primeiro procedimento adotado foi a realização de uma análise dos elementos teóricos que sustentam este trabalho. 0 segundo passo consistiu da escolha da organização para a realização do estudo. A escolha dessa organização ocorreu por questões de acessibilidade aos dados e aos entrevistados que seriam necessários para a pesquisa. 


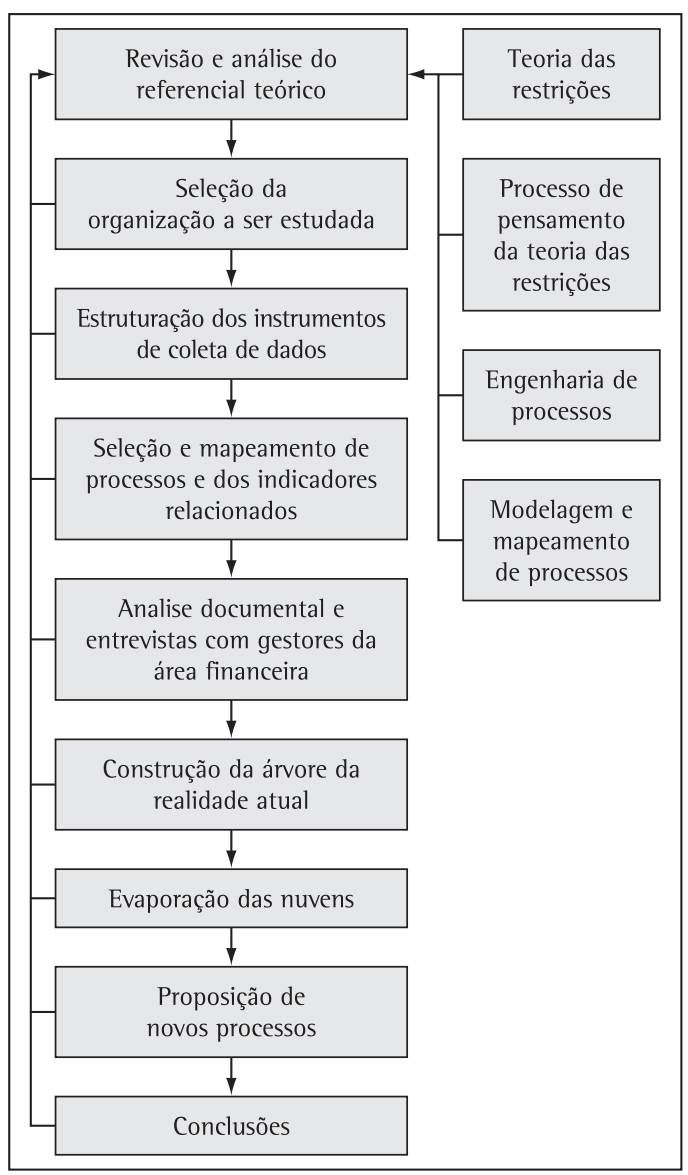

Figura 2. Estrutura de execução da pesquisa. Fonte: os autores.

Em seguida, foram definidos os instrumentos de coleta de dados, que consistiram de questionários semiestruturados e análise de relatórios e informações gerenciais. 0 próximo passo foi a seleção dos processos, subprocessos e indicadores relacionados que seriam analisados. Uma vez selecionados os subprocessos e os indicadores relacionados, foram identificados as pessoas a serem entrevistadas e os documentos que serviriam para validar esses depoimentos. Inserir os indicadores no mapeamento e modelagem dos processos teve por objetivo fornecer um conjunto maior de elementos para a construção da Árvore da Realidade Atual e, por consequência, contribuir na definição do problema através da elaboração da evaporação das nuvens. Com base nas transcrições das entrevistas das pessoas foram elencados os efeitos indesejados percebidos.

De posse do quadro dos efeitos indesejados percebidos nos subprocessos e nos indicadores construiu-se uma Árvore da Realidade Atual para cada um dos subprocessos. Após a construção das ARAs individualizadas, elas foram integradas e outros efeitos indesejados foram identificados por meio da revisão das ARAs individuais e da ARA integrada. $\mathrm{Na}$ sequência construiu-se o questionamento da causa que pode alavancar a melhoria do sistema através da evaporação das nuvens. Como resultado foi encontrada uma injeção para resolução do conflito. A partir do resultado da evaporação das nuvens os processos e os indicadores associados foram redesenhados.

\section{0 caso}

A organização que serviu de objeto para o trabalho foi uma instituição de ensino superior do Sul do Brasil. Essa organização presta serviço de ensino de graduação, extensão e pós-graduação. Além disso, desenvolve pesquisas no âmbito dos seus programas de pós-graduação. 0 trabalho de coleta dos dados foi iniciado em junho de 2000 e nele foram identificados 11 macroprocessos, 80 processos principais, 441 subprocessos e 1.900 atividades (transações de negócio). A realização desse mapeamento contou com uma equipe de 150 pessoas de diversas áreas da IES.

A quantidade elevada de macropocessos tornaria inviável a realização do estudo. Por isso, realizou-se um corte inicial selecionando os processos associados a uma área específica da organização. Nesse caso, a área administrativo-financeira foi escolhida em função de ser uma área crítica nessa ou em outra empresa. Diversos subprocessos foram analisados, mas para viabilizar a realização deste trabalho foram selecionados um subprocesso e os indicadores relacionados, dentre os mapeados: 0 subprocesso de elaboração do orçamento. A seguir se apresentará a apreciação do caso.

\subsection{O que mudar?}

Nessa parte serão apresentados: o atual subprocesso, os indicadores vinculados e os impactos sistêmicos observados na Árvore da Realidade Atual. Após isso serão propostos o redesenho do processo e a redefinição dos indicadores.

\subsubsection{O mapeamento do processo atual (AS-1S)}

0 subprocesso de elaboração do orçamento visa calcular e consolidar o conjunto de necessidades monetárias da instituição, para determinado período, discutido e aprovado nas instâncias competentes. 
Consolida as premissas orçamentárias através das estimativas de créditos matriculados, índices de inflação e dissídio, necessidades de investimentos e gratuidades e nas séries históricas de evasão e inadimplência. Realizada a consolidação, prepara-se a base orçamentária com ajustes ou ampliação de contas, tendo por base o plano de investimento e seus respectivos projetos ou produtos.
Elabora-se o orçamento por centros de custos, áreas de responsabilidade, áreas acadêmicas e de apoio. Após isso, realizam-se os ajustes dos recursos, mediante avaliação dos gestores das áreas acadêmicas e de apoio. Essa interação ocorre até que haja a equalização das diferenças ou até que o prazo limite para envio às instâncias superiores se faça premente.

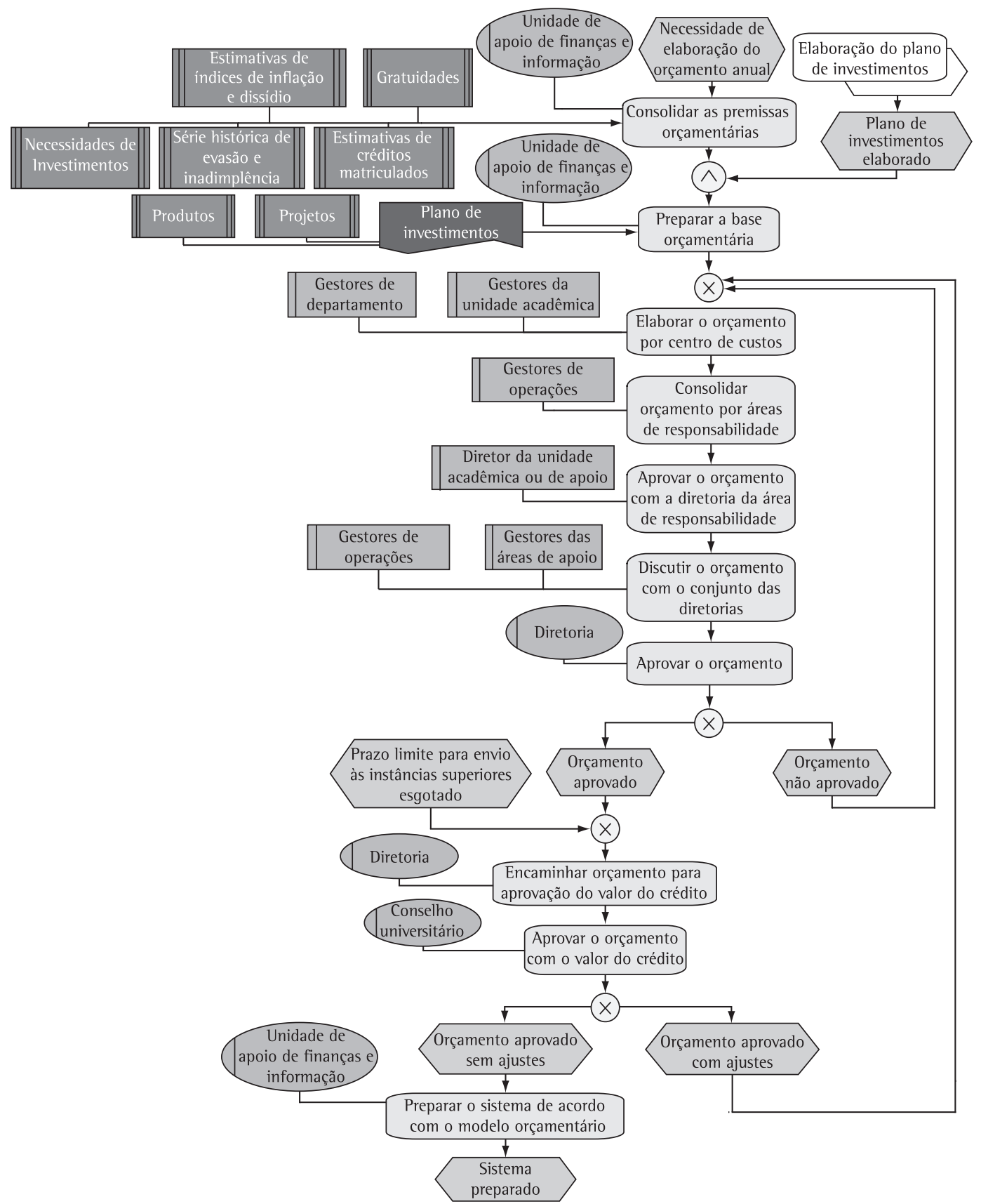

Figura 3. Fluxograma do subprocesso de elaboração do orçamento. Fonte: os autores. 
Envia-se o orçamento para o Conselho Universitário (Consun), que o aprova ou não (disparando novamente o subprocesso). Sendo aprovado, realizam-se os ajustes necessários (se for o caso) e prepara-se o sistema de acordo com o modelo orçamentário. A representação gráfica pode ser vista na Figura 3. Além do processo, sucintamente explicitado, na sequência se evidenciam os principais indicadores associados. Esses indicadores são avaliados pelos gestores, em particular, e pela IES, em geral.

\subsubsection{Indicadores atuais vinculados ao processo (AS-1S)}

Os indicadores são medidos localmente em relação aos produtos sob sua gestão sem uma visão do impacto de suas ações no todo da IES. Assim sendo, os indicadores atuais vinculados ao processo são os seguintes:

a) Índice de produtividade: esse indicador tem por objetivo verificar o nível de produtividade de um determinado produto universitário, através do retorno sobre cada unidade monetária de despesas deste, ou área que está sob análise. Tem-se a expectativa que esse índice aumente, isto é, espera-se que para cada real em despesas haja uma quantidade superior de receitas;

Índice de produtividade $=\frac{\text { Receita líquida }_{\mathrm{i}}}{\text { Despesa total }_{\mathrm{i}}}+\stackrel{+}{\text { Despesa financeira }_{i}}$

b) Diferença orçado/realizado: por sua vez, esse indicador demonstra as diferenças entre os resultados contratados em cada um dos produtos universitários e o resultado efetivamente alcançado. Almeja-se que esse indicador seja o mais próximo a 1 , fazendo assim que a previsão se concretize, ou que seja superior a 1 , superando as expectativas. A busca é pelo equilíbrio, assim o ideal é que o índice demonstre que as previsões são acuradas;

$$
\begin{gathered}
\begin{array}{c}
\text { Resultado operacional } \\
\text { realizado }
\end{array} \\
\begin{array}{c}
\text { Resultado operacional } \\
\text { orçado }_{i}
\end{array}
\end{gathered}
$$

c) Nível de realização das receitas: o nível de realização das receitas tem por objetivo demonstrar as diferenças entre as receitas previstas e realizadas de um determinado produto universitário ou área de gestão "i". Complementarmente a esse indicador, tem-se o índice de evolução das receitas em termos nominais e reais, também concernente a uma determinada área ou produto universitário, onde “i” é um determinado produto ou área e " $k$ " é um determinado período de análise. A expectativa é que ambos os indicadores aumentem ao longo do tempo.

$$
\begin{aligned}
& \text { Total das receitas } \\
& \text { realizadas } \\
& \text { Total das receitas } \\
& \text { previstas } \\
& \text { Receitas realizadas }{ }_{i k} \\
& \underset{\text { nominais/reais }}{\text { Evoluc̃o das receitas }}=\frac{\text { Receitas realizadas }_{\text {ik-1 }}}{\text { Receitas previstas }_{\text {ik-1 }}}
\end{aligned}
$$

Os valores devem ser analisados nominalmente e em termos reais (considerando a inflação acumulada no período).

Esses subprocessos integrados a esses indicadores, apresentam uma série de efeitos indesejados que são sustentadas por um determinado número de causas de forma interrelacionadas, essas relações serão descritas a seguir. Essas relações serão realizadas e avaliadas por meio da construção da Árvore da Realidade Atual.

\subsection{3. Árvore da Realidade Atual do processo de elaboração do orçamento (AS-1S)}

A Árvore da Realidade Atual diagramada na Figura 4 identifica os principais efeitos indesejados e as possíveis causas no subprocesso orçamentário. $\mathrm{Na}$ ARA verifica-se o efeito indesejado principal: o orçamento não representa a estratégia da IES.

Como o subprocesso de orçamento é realizado individualmente e, após isso, existe a negociação orçamentária entre as diversas áreas, verifica-se a necessidade da inserção de variadas seguranças nos diversos níveis organizacionais. Isso acarreta um valor superestimado de recursos necessários para cada área individualmente. Também entram componentes sociais e comportamentais no processo de negociação que pode ter como consequência o desgaste de ter os recursos cortados etc.

0 planejamento das áreas não é feito de forma integrada. Cada área elabora suas atividades individualmente, e as ações que poderiam ser realizadas de maneira conjunta ocorrem eventualmente, pois dependem da boa vontade e do relacionamento dos gestores das áreas ou departamentos.

Um aspecto relevante a ser considerado é a extrapolação do orçamento a partir das séries anteriores. Ainda que se façam as correções nos dados anteriores a partir do novo mercado, um processo importante não ocorre: a discussão da IES e suas práticas no período passado e para o período que se projeta. A falta dessa discussão propicia um 


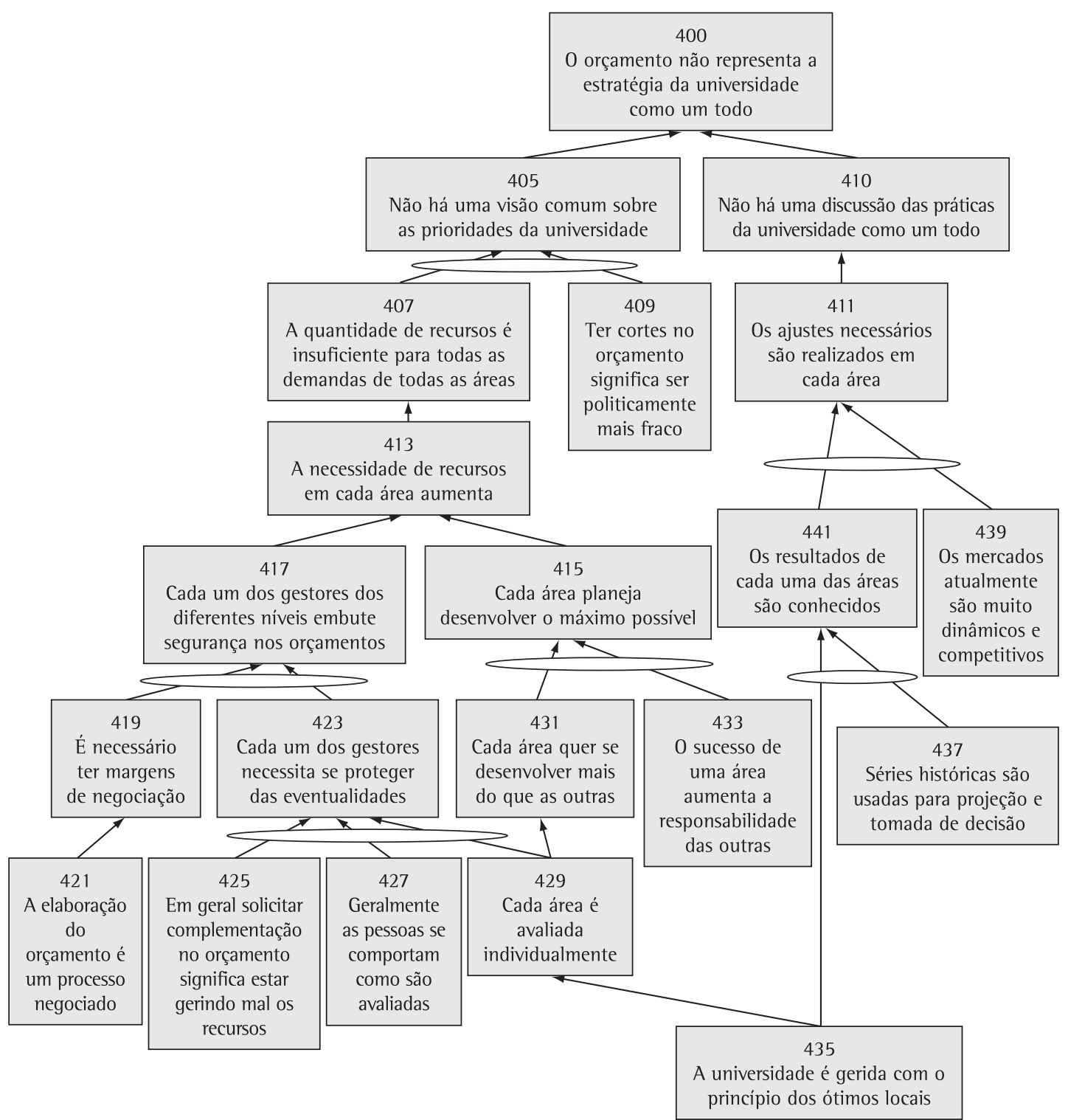

Figura 4. Fluxograma do subprocesso de elaboração do orçamento. Fonte: os autores.

ambiente de visão fragmentada do negócio, que por sua vez estimula a competição interna entre as áreas e as gerências.

\subsection{Evaporação das nuvens}

Através da Árvore da Realidade Atual, identificou-se que o principal problema era a não representatividade da estratégia da IES no orçamento. A realização da Árvore da Realidade Atual, construída a partir das pessoas entrevistadas na pesquisa, sobre as razões pelas quais o orçamento não reflete a estratégia da IES, apontou que a instituição de ensino superior é gerida com o princípio dos ótimos locais. Ou seja, cada departamento procura o melhor resultado para si, independente dos efeitos sistêmicos para toda a organização. Assim, utilizou-se o diagrama de evaporação das nuvens (Figura 5) para identificar os pressupostos que sustentam a causa principal. Por consequência, procurou-se trazer uma ou mais injeções que pudessem romper esses bloqueios mentais para a melhor solução. Uma solução que não seja de compromisso, onde cada uma das partes cede na busca de um consenso.

Para que isso ocorra é necessário estabelecer um objetivo em comum entre ambas as visões gerenciais. Dessa forma, se estabelece que o objetivo 


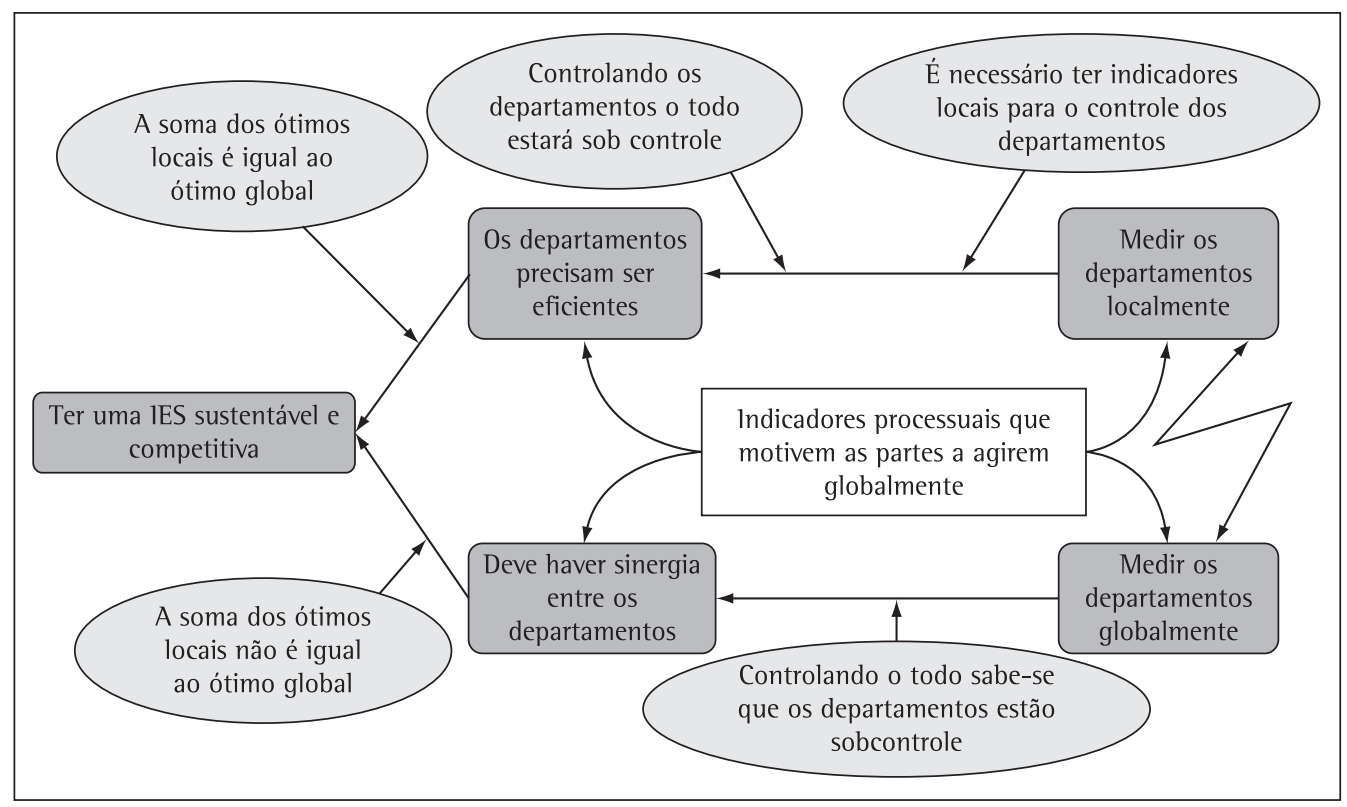

Figura 5. Diagrama de evaporação das nuvens - Causa básica da Árvore da Realidade Atual. Fonte: os autores.

comum é: "ter uma universidade sustentável e competitiva". Entretanto, para que se obtenha esse objetivo comum, têm-se dois caminhos: a) os departamentos precisam ser eficientes; e b) deve haver sinergia entre eles.

Essas posições antagônicas são sustentadas pelos pressupostos destacados nos círculos da Figura 5. Para atender os pressupostos é necessário medir os departamentos localmente, pois controlando cada um dos departamentos, e se cada um atingir um nível melhor, o todo estará melhorando, e, ainda, os que não estão contribuindo poderão sofrer as ações corretivas necessárias.

Para lidar com esse problema, foi apresentada a injeção de criação de indicadores processuais que motivem as partes a agir globalmente. Sob essa lógica, os departamentos trabalham para o todo. Nesse sentido há a colaboração com os resultados que sejam o melhor para a organização, pois a sustentabilidade do todo (organização) é também a sobrevivência das partes (departamentos/áreas). Contribuindo para a melhoria da organização, os processos foram redesenhados e os indicadores alinhados à injeção. Essas proposições são apresentadas na sequência do trabalho.

\subsection{A Proposição de redesenho do processo de elaboração do orçamento (TO-BE)}

A seguir é apresentada a proposição de redesenho do processo alinhado com a injeção mencionada.

\subsubsection{Processo redesenhado de elaboração do orçamento - (TO-BE)}

A elaboração do orçamento é um desdobramento da projeção e análise econômico-financeira da IES. Nesse sentido expressam-se em números as opções estratégicas para a universidade como um todo e pela carteira de produtos ofertados.

Assim, o subprocesso começa pela análise do conjunto dos produtos e as estimativas de demanda e, ao mesmo tempo, consolidam-se as receitas dos diferentes produtos universitários e os custos totalmente variáveis diretos a esses produtos. Obtém-se, portanto, o ganho total da IES.

Com base nas informações dos sistemas de informação, totalizam-se as despesas operacionais e se visualiza o comportamento dessas despesas. A partir dessa análise procuram-se elaborar proposições de melhorias para maximizar os benefícios com os gastos nesses recursos. Busca-se do subprocesso do plano de investimento o orçamento de investimentos da IES para o próximo período.

Posto isso, deve-se realizar o fechamento do resultado geral da instituição de ensino superior considerando as receitas, os ganhos, as despesas operacionais e os investimentos. Nesse momento em que a peça orçamentária está finalizada, a alta administração da IES realiza uma análise do alinhamento entre o orçamento e as estratégias da IES. A Figura 6 apresenta graficamente esse subprocesso. 
Caso o orçamento expresse as estratégias da universidade, fecha-se a questão das metas de ganhos, despesas operacionais e retorno sobre 0 investimento esperado. Aprova-se o orçamento no Conselho Universitário (Consun) e ocorre a carga no sistema para o controle do orçado/realizado e do atendimento das metas. Caso contrário, há três ações que devem ser realizadas: i) reposicionar as despesas operacionais para sustentar a estratégia; ii) realinhar o plano de investimentos às estratégias; e iii) reposicionar os produtos para sustentar as estratégias. A seguir serão propostos os indicadores para o processo redesenhado em questão.

\subsubsection{Indicadores (TO-BE)}

Buscando fornecer uma alternativa não apenas em termos de processos, como também em termos de indicadores, abaixo se descrevem os indicadores que, em tese, proporcionam uma visão geral e que procuram o ótimo global para a organização.

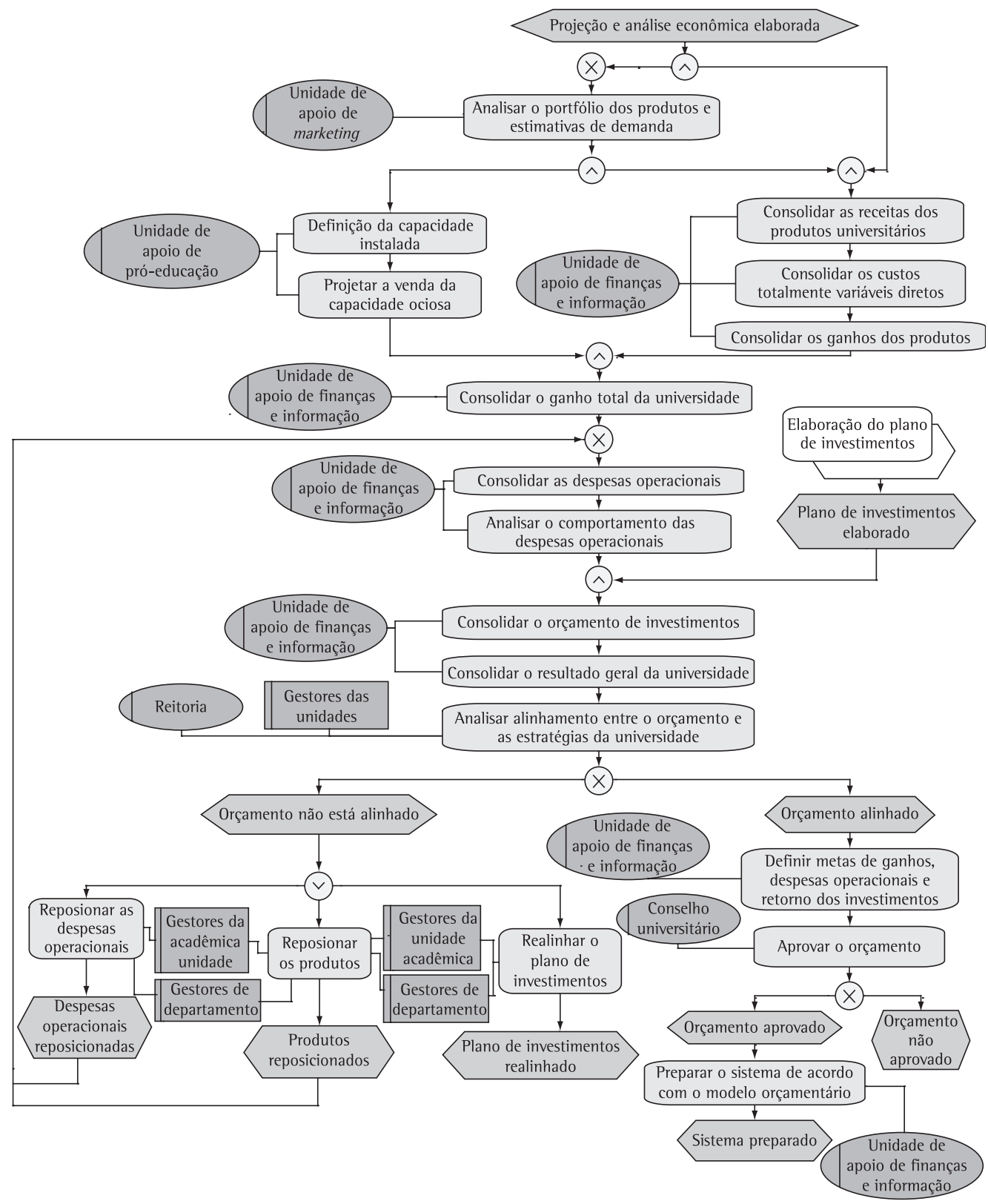

Figura 6. Fluxograma do subprocesso redesenhado de elaboração do orçamento. Fonte: os autores. 
a) Índice de aproximação da despesa operacional geral: através desse índice, verifica-se se a despesa operacional total projetada foi realizada de modo efetivo, ou melhor, reduzida. Sistemicamente, esse indicador deve ser atingido no todo para premiação ou punição das partes. Esse indicador poderá ser otimizado para se atingir outros dois indicadores do subprocesso de análise e projeção financeira (retorno sobre o investimento geral e o lucro líquido geral). 0 comportamento esperado é a menor diferença entre o previsto e o realizado ou, se for o caso, a redução da despesa operacional efetiva em relação à projetada;

$$
\begin{aligned}
& \text { Indice de aproximação da } \\
& \text { despesa operacional geral }
\end{aligned}=\frac{\begin{array}{c}
\text { Despesa operacional } \\
\text { total realizado }
\end{array}}{\begin{array}{c}
\text { Despesa operacional } \\
\text { total projetado }
\end{array}}
$$

b) Índice de aproximação do ganho total da IES: esse indicador tem por objetivo interagir diversas áreas da IES para atingir a meta de ganho da IES. Isso ocorre pela comparação entre o ganho da IES, estabelecido para o período, e o efetivamente ocorrido. Acompanhando no nível global esse indicador, obriga-se a interação de diversas áreas para essa consecução e, consequentemente, os benefícios de ter atingido essa meta.

No que se refere ao marketing, haverá uma pressão para que as previsões sejam as mais acuradas possíveis. Em relação aos gestores poderá haver uma interação para maior venda e, por consequência, maior geração de ganho para o todo ou, ainda, as partes poderão procurar otimizações nos custos variáveis para que a meta de ganho total da IES seja atingida. Espera-se que esse indicador seja o mais próximo possível do planejado ou, se for o caso, superior ao planejado;

$$
\begin{gathered}
\text { Índice de aproximação } \\
\text { do ganho total }
\end{gathered}=\frac{\sum_{\mathrm{i}=1}^{\mathrm{n}} \text { Preço de vendastos variáveis diretos }}{\mathrm{i}}
$$

c) Índice de aproximação do lucro líquido da universidade: da mesma forma que o indicador anterior, esse tem por objetivo premiar ou punir os gestores da universidade como um todo em relação ao indicador de atingimento do lucro íquido total necessário para sobrevivência da universidade. Espera-se que esse indicador seja o mais próximo possível do planejado ou, se for o caso, superior ao planejado;

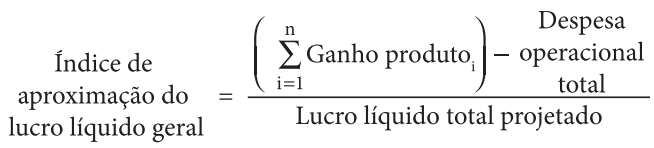

d) Índice de aproximação do retorno sobre o investimento geral: esse índice verifica o retorno esperado pelos investimentos realizados. Assim, constatam-se os retornos efetivos em termos financeiros, alinhado aos outros indicadores. Os gestores serão avaliados de acordo com a consecução do índice de forma geral. Espera-se que esse indicador seja o mais próximo possível do planejado ou, se for o caso, superior ao planejado.

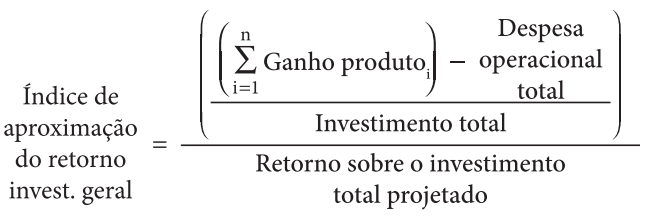

A seguir serão expostas as considerações finais da pesquisa. Na próxima seção se procurará avançar na reflexão sobre a utilização conjunta da engenharia de processos de negócios e o processo de pensamento da Teoria das Restrições.

\section{Conclusões}

0 trabalho ilustrou, por meio de um caso prático, como a engenharia de processos pode ser utilizada para contribuir com o processo de pensamento da Teoria das Restrições. Os conceitos e técnicas da engenharia de processos possibilitaram sistematizar a abordagem da Teoria das Restrições para diversas áreas e processos da organização. Por limitações de espaço do artigo, apresentaram-se os resultados atingidos com a análise e redesenho de apenas um subprocesso da IES em estudo.

A engenharia de processos possibilitou, por meio da abordagem proposta, a condução de discussão através do diagnóstico das problemáticas organizacionais a partir dos processos modelados. Durante a fase de modelagem dos processos, além da descrição das atividades em si, foi levantado um conjunto de percepções que enriqueceram a construção das árvores da realidade atual.

Um fator de contribuição relevante da engenharia de processos é fornecer um ponto de partida para a construção das ARAs. Isso ocorre uma vez que, no arcabouço teórico da Teoria das Restrições, não há indicativos sobre quais os pontos iniciais para construir as árvores da realidade atual. Assim, por meio da modelagem dos processos, faz-se uma construção botton-up partindo dos efeitos indesejados nas operações diárias até a consolidação em nível de organização.

Isso permitiu, no caso específico, o desenvolvimento de diagnóstico sistêmico dos processos da área econômico-financeira, por 
meio da Árvore da Realidade Atual. Observou-se a existência de um reduzido número de causas básicas responsáveis para uma quantidade maior de efeitos indesejáveis na organização em tela.

A gestão pelos ótimos locais, motivando as partes (unidades, departamentos, programas etc.) a buscar a sua maximização individual, traz como consequência indesejada uma série de ações locais, as quais podem prejudicar o desempenho global da organização. Outra questão relevante é que o desenho dos processos e indicadores atuais pode sustentar um conjunto de efeitos indesejados que, uma vez analisados sistematicamente, podem ser redesenhados alterando os efeitos sobre a organização.

Assim sendo, o trabalho procurou contribuir para a construção de um elo entre a abordagem da engenharia de processos e do processo de pensamento da Teoria das Restrições por meio da utilização de um conjunto de procedimentos advindos desses arcabouços teóricos. Nesse sentido, torna-se possível a realização de outras pesquisas que possam contribuir para a aproximação dessas abordagens. Por exemplo, Migon (2010) desenvolveu um aplicativo para operacionalização da análise de processos de negócio a partir do processo de pensamento da Teoria das Restrições. 0 ambiente colaborativo desenvolvido permite a rastreabilidade dos efeitos indesejados diretamente às atividades dos processos de negócios. Além disso, a técnica empregada para levantamento dos efeitos indesejados amplia as possibilidades de aplicação do processo de pensamento da Teoria das Restrições

Enfim, as possibilidades de pesquisa estão presentes para desenvolvimento. Como sugestão para outros trabalhos, algumas questões parecem relevantes. Primeiro, a utilização das árvores de pré-requisitos e de transição pode ser apropriada para a implementação das mudanças nos processos. Segundo, a utilização da Árvore da Realidade Atual para avaliação de indicadores e o próprio estabelecimento de indicadores processuais, a partir de um ponto de vista sistêmico, são temáticas a ser melhor exploradas. Terceiro, a definição de critérios para a construção e a avaliação dos indicadores de um ponto de vista sistêmico parecem ser necessárias. Quarto, a avaliação dos indicadores a partir da lógica da Teoria das Restrições pode contribuir para o alinhamento das ações operacionais à estratégia da empresa, ou, ainda, servir como baliza para o empreendimento de ações nas empresas. Quinto, a consolidação de árvores da realidade atual dos processos de negócio, em particular, pode revelar pontos de alavancagem para os diferentes processos da organização, em geral. Nesse sentido, trabalhos que apresentem a integração de diferentes ARAs podem abrir outras possibilidade de análise e, sobretudo, de ação.

Como pôde ser observado, abre-se um campo amplo de possibilidades de pesquisa para além da identificação dos possíveis benefícios da aplicação da Teoria das Restrições. A inserção da Teoria das Restrições no ambiente dos processos de negócios pode contribuir para evidenciar as restrições políticas ou gerenciais que não são facilmente observáveis. Este artigo, pela sinergia entre engenharia de processos de negócios e o processo de pensamento da Teoria das Restrições, contribuiu como uma sistemática para a exposição desses tipos de restrições.

\section{Referências}

ALVAREZ, R. R. Análise comparativa de metodologias para análise, identificação e solução de problemas. Dissertação (Mestrado em Engenharia da Produção)-Universidade Federal do Rio Grande do Sul, Porto Alegre, 1995.

ANTUNES Jr. J. A. V. et al. Critical issues about the theory of constraints thinking process - a theoretical and practical approach. In: PRODUCTION AND OPERATION MANAGEMENT SOCIETY - POMS, 15., 2004, Cancun. Proceedings...

BLACKSTONE, J. H. Theory of constraints - a status report. International Journal of Production Research, v. 39, n. 6, p. 1053-1080, 2001.

BRYMAN, A. Quantity and quality in social research. London: Unwin Hyman, 1988.

CAULliRAUX, H.; CAMEIRA, R. A consolidação da visão por processos na engenharia de produção e possíveis desdobramentos. Rio de Janeiro: Grupo de Produção Integrada/COPPE-EE//UFRJ, 2000.

CHAKRAVORTY, S. S.; BRIAN ATWATER, J. Bottleneck management: theory and practice. Production, Planning \& Control, v. 17, n. 5, p. 441-447, 2006.

COX, J.; SPENCER, M. S. Manual da teoria das restrições. Porto Alegre: Bookman, 2002.

DAVENPORT, T. H. Mission critical: realizing the promise of enterprise systems. Boston: Harvard Business School Press, 2000.

DUBE, L.; PARE, P. Rigor in information systems positivist case research: currente pratices, trends, and recomendations. MIS Quaterly, v. 27, n. 4, p. 597-635, 2003.

DYER Jr., W. G.; WILKINS, A. L. Better stories, not better constructs, to generate better theory: a rejoinder to Eisenhardt. Academy of Management Review, v. 16, n. 3, p. 613-619, 1991.

EINSENHARDT, K. M. Building theories from case study research. Academy of Management Review, v. 14, p. 532-550, 1989.

EINSENHARDT, K. M. Better stories and better constructs: the case for rigor and comparative logic. Academy of Management Review, v. 16, n. 3, p. 620-627, 1991. 
EINSENHARDT, K. M.; GRAEBNER, M. E. Theory building from cases: opportunities and challenges. Academy of Management Review, v. 50, n. 1, p. 25-32, 2007.

ELLRAM, L. M. The use of the case study method in logistics research. Journal of Business Logistics, v. 17, n. 2, p. 93-138, 1996.

GOLDRATT, E. M. What is thnig called theory of constraints and how shoud it be implemented? New York: Noth River Press, 1990.

GOLDRATT, E. M. A síndrome do palheiro: garimpando informações num oceano de dados. São Paulo: C. Fulmann, 1991.

GOLDRATT, E. M. A corrida pela vantagem competitiva. São Paulo: C. Fulmann, 1992.

GOLDRATT, E. M. Não é sorte: a aplicação do processo de raciocínio da teoria das restrições. São Paulo: Nobel, 2004.

GOLDRATT, E. M. Standing on the shoulders of giants production concepts versus production applications: the hitachi tool engineering example. Gestão \& Produção, v. 16, n. 3 , p. $333-343,2009$.

GROVER, V.; KETTINGER, W. R. Process think: winning perspectives for business change in the information age. Idea Group lnc, 2000.

GUPTA, M. C., BOYD, L. H., Theory of Constraints: a theory of operations management, International Journal of Operations \& Production Management, v. 28, n. 10, p. 991-1012, 2008.

HAMMER, M. E.; CHAMPY, J. Reengenharia: repensando a empresa em função dos clientes, da concorrência e das grandes mudanças da gerência. Rio de Janeiro: Campus, 1994.

HUNT, V. D. Process mapping: how to reengeneer your business processes. New York: John Wiley \& Sons, 1996.

JOHANSSON, H. J. et al. Processos de negócios. São Paulo: Pioneira, 1995.

KIM, S.; MABIN, V. J.; DAVIES, J. The theory of constraints thinking process: retrospect and prospect. International Journal of Operations \& Production Management, v. 28, n. 2, p. 155-184, 2008.

KINGMAN, O. The thinking processes and effective problem solving. In: CONSTRAINT MANAGEMENT SYMPOSIUM AND TECHNICAL EXHIBIT - APICS, 1996, Detroit. Proceedings... p. 110-116.

KLEIN, D. J.; DEBRUINE, M. A thinking process for establishing management polices. Review of Business, v. 16, n. 3, p. 31-37, 1995.

LACERDA, D. P. No sentido do mundo dos ganhos: uma proposta de transição através do redesenho de processos em uma instituição de ensino superior. Dissertação (Mestrado em Administração)-Universidade do Vale do Rio dos Sinos, São Leopoldo, 2005.

MIGON, L. B. Identificação e representação de desvios de processos de negócio: aplicação no estudo da cadeia de amostragem de petróleo. Dissertação (Mestrado em Informática)-Universidade Federal do Rio de Janeiro, Rio de Janeiro, 2010.
MUSA, P. F.; EDMONSON, V. C.; MUNCHUS, G. Analyses of information system students' applications of two holistic problem solving methodologies. Journal of Information Systems Education, v. 16, n. 4, p. 391-408, 2006.

NOREEN, E.; SMITH, D.; MACKEY, J. T. A teoria das restrições e suas implicações na contabilidade gerencial. São Paulo: Educator, 1996.

OU-YANG, C.; LIN, Y. D. BPMN-based business process model feasibility analysis: a petri net approach. International Journal of Production Research, v. 46, n. 14, p. 3763-3781, 2008.

PAIM, R. Engenharia de processos: análise do referencial teórico-conceitual, instrumentos, aplicações e casos. Dissertação (Mestrado em Engenharia de Produção)COPPE-UFRJ, Rio de Janeiro, 2002.

PAIM, R. et al. Engenharia de processos de negócios: aplicações e metodologias. In: ENEGEP, 22.. 2002. Anais...

PAIM, R. et al. Gestão de processos: pensar, agir, aprender. Porto Alegre: Bookman, 2009.

PAIM, R.; CAULLIRAUX, H.; CLEMENTE, R. Engenharia de processos: equipes, estrutura e conhecimentos para aprimoramento organizacional. In: ENEGEP, 23., 2003. Anais..

PIDD, M. Modelagem empresarial: ferramentas para tomada de decisão. Porto Alegre: Bookman, 1998.

RODRIGUES, L. H. A aplicação do processo de pensamento da teoria das restrições no ensino de conceito básicos de administração das operações. In: ENANPAD, 28., 2004, Curitiba. Anais...

RUMMLER, G. A.; BRACHE, A. P. Improving performance: how to manage the white space on the organizational chart. $2^{\text {nd }}$ ed. San Francisco: Jossey Bass, 1995.

SALERNO, M. S. Projeto de organizações integradas e flexíveis: processos, grupos e gestão democrática via espaços de comunicação-negociação. São Paulo: Atlas, 1999.

SCHEER, W. ARIS - Business Process Modeling. $2^{\text {nd }}$ ed. Berlin: Springer Verlag, 1999.

TSCHESCHNER, W. Transformation from EPC to BPMN Business Process Technology, v. 1, n. 3, p. 7-21, 2006.

VERNADAT, F. B. Enterprise modeling and integration: principles and applications.London: Chapman \& Hall, 1996.

VILLELLA, C. S. S. Mapeamento de processos como ferramenta de reestruturação e aprendizado organizacional. Dissertação (Mestrado em Engenharia de Produção)Universidade Federal de Santa Catarina, Florianópolis, 2000.

WATSON, K. J.; BLACKSTONE, J. H.; GARDINER, S. C. The evolution of a management philosophy: the theory of constraints. Journal of Operations Management, v. 25 , p. 387-402, 2007.

YIN, R. K. Estudo de caso: planejamento e métodos. 2. ed. Porto Alegre: Bookman, 2001. 


\title{
Evaluating the synergy of business process engineering and theory of constraints thinking process
}

\begin{abstract}
This paper presents a joint application of Business Process Engineering and the Thinking Process of the Theory of Constraints. Business Process Engineering has been used as a process modeling tool in order to describe the "as is" situation. The Thinking Process is used as an analytical tool for the critical processes. This analysis contributes for the clarification and convergence to the core problem in a given situation, providing a systemic and shared vision. The case study investigated a Higher Education Institution processes. A Current Reality Tree was created for each process, which derivate in Evaporating Cloud Diagrams in order to find insights for process improvement. Based on the Current Reality Tree and the Evaporating Clouds Diagram the processes was redesigned. The results of this approach were very promising, once they reached: i) a systematic analysis for the processes; e; ii) a systemic and shared vision of the relationships of the cause and effect involved in the processes studied.
\end{abstract}

\section{Keywords}

Theory of constraints. Thinking process. Engineering of process. Systemic analysis.

Anexo 1. Legendas utilizadas para a modelagem de processos pela metodologia ARIS.

\begin{tabular}{|c|c|c|c|}
\hline Atividade & Atividade inserida no processo & Evento & $\begin{array}{l}\text { "Disparador" de atividades ou "resultado" das } \\
\text { mesmas }\end{array}$ \\
\hline $\begin{array}{l}\text { Interface de } \\
\text { processo }\end{array}$ & Interface entre processos & (1) & $\begin{array}{l}\text { "E": todas as saídas são seguidas, ou todas as } \\
\text { entradas são necessárias }\end{array}$ \\
\hline (v) & $\begin{array}{l}\text { "Ou”: podem ser seguidos um ou } \\
\text { mais caminhos; ou, no mínimo, uma } \\
\text { das entradas deve existir para saída }\end{array}$ & X & $\begin{array}{l}\text { "Ou exclusivo": a partir desse ponto, apenas } \\
\text { um dos caminhos será seguido }\end{array}$ \\
\hline$\left(\begin{array}{c}\text { Unidade } \\
\text { organizacional }\end{array}\right.$ & Unidade organizacional & Cargo & Cargo dentro da estrutura da organização \\
\hline Documento & Meio físico contendo informações & Informação & $\begin{array}{l}\text { Qualquer informação contida em um } \\
\text { documento ou sistema }\end{array}$ \\
\hline
\end{tabular}

Fonte: adaptado de Scheer (1999). 